\title{
The Why and How of Fostering International Academic Exchange at Schools in Taiwan
}

\author{
Shih-Chang Lee ${ }^{1}$, Tien-Ling $\mathrm{Hu}^{1} \&$ Hsuan-Fu $\mathrm{Ho}^{1}$ \\ ${ }^{1}$ National Chiayi University, Taiwan, Province of China \\ Correspondence: Hsuan-Fu Ho, National Chiayi University, Taiwan, Province of China. E-mail: \\ hfho@mail.ncyu.edu.tw
}

Received: December 10, 2017

Accepted: January 12, 2018

Online Published: January 15, 2018

doi:10.5539/ijbm.v13n2p87

URL: https://doi.org/10.5539/ijbm.v13n2p87

\begin{abstract}
A high quality workforce with global competence is the key to survive today's globalized market. The Taiwan government published its White Paper of International Education for Primary and Secondary Schools in 2011. This research examined the relative importance of objectives of international education announced by the government, and to determine the most efficient international academic exchange approaches for achieving the objectives. Analytic hierarchy process (AHP) was adopted as the major calculation instrument, and a self-developed questionnaire was administered to school principals in Taiwan. The research results indicated that cultivating keen observation capability for international comparison, understanding critical global issues, and understanding interdependence of global relationships are the most important objectives for international education at the primary and secondary levels. Moreover, as different implementation approaches may contribute to different objectives, it is important for school principals to select the right implementation approaches to fit their unique environmental and educational focus.
\end{abstract}

Keywords: Internationalization, globalization, knowledge economy, international academic exchange, AHP

\section{Introduction}

The trend of globalization has brought new opportunities for international cooperation, but has simultaneously created ferocious competition among nations throughout the world. As a high quality workforce with global competences is a prerequisite for surviving the new global market, countries around the world are fostering international education at different age levels to enhance graduates' and nations' international competitiveness.

Taiwan is no exception. The Taiwan government published its White Paper of International Education for Primary and Secondary Schools in 2011, which set out a variety of strategies to teach fundamental international knowledge and competencies to primary and high school students. The four major goals identified in the white paper were to enhance students' national identity, international literacy, global competition/cooperation, and global responsibility. Thereafter, four major dimensions of implementing objectives were announced to achieve the four goals: international curriculum development, international academic exchange, teacher professional development, and internationalization of school campuses. Among all the dimensions of implementation, the government and school stakeholders focus mostly on the international academic exchange dimension, allocating a great deal of funds to implementing programs under this dimension. However, as not enough knowledge and experiences have been associated with the international academic exchange in Taiwan, many principals have lamented that they face tremendous difficulties in carrying out their international exchange programs.

Thus, this research endeavored to identify the relative importance of the objectives of international education as perceived by principals in Taiwan and to determine how a variety of international academic exchange approaches might accomplish the aforementioned objectives. The research questions are as follows:

1. What is the relative importance of each objective of international education as perceived by elementary and junior high school principals?

2. How efficient are the international academic exchange approaches in achieving the objectives of international education?

3. Are there perception variations among school principals with different geo-demographic backgrounds? 


\section{Globalization and Internationalization of Education}

At the turn of 21st century, the progress in transportation and communication technology accelerated the impact of globalization. Although globalization creates a whole new world full of opportunities for prosperity, at the same time it forms ferocious competition among countries throughout the world (Childress, 2009; Gao, 2015). In today's global economy, knowledge, information, and ideas are the keys to creating economic values, and countries around the world are endeavoring to nurture a high quality labor force that not only possesses professional knowledge and skills, but is also talented in understanding the global issues and trends. As a result, the internationalization of education has been fostered by countries in an effort to answer this new global labor market need (Beerkens, 2008; Youssef, 2014).

The internationalization of education is a process that integrates the international and intercultural concepts into the teaching, learning, researching, and service activities in the educational institutions at different age levels (Pandit, 2009). The major goal of the internationalization of education, in general, is to nurture students with global competencies, by which they are able to succeed in a global market of international and multicultural settings (Pandit, 2009). Historically, international education was only available for the wealthy, but today it is more affordable as transportation and communication techniques have improved. Although international education often occurs at the higher educational level, it is expected to become popular at the elementary and secondary school levels because governments assumed that students learn quicker if they start younger. The Taiwan government thus ambitiously released its White Paper of International Education for Primary and Secondary Schools in 2011 to promote the sufficient provision of a talented workforce with international competencies to ensure its international competitiveness in today's new economy.

\subsection{Objectives of Internationalization of Education}

Although almost all countries in the world are currently endeavoring to promote the internationalization of education, their policy objectives are somewhat different. Seeber, Cattaneo, Huisman, and Paleari (2016) indicated that the rationales for countries to adopt internationalization can be viewed from three different levels: macro, meso, and micro. From the macro level, educational institutions are willing to educate a high quality labor force with adequate global competences to survive the new global market and to seek out more international cooperation opportunities to address global challenges such as health, climate change, and food supply. From the meso level, educational institutions are expecting to enhance their international prominence, to improve the quality of teaching and learning, and to gain profits from international students. Finally, from the micro level, educational stakeholders are participating in internationalization programs to broaden their international aspects, improve their international competence, and enhance their international interaction abilities.

Ho, Lin, and Yang (2015) argued that the benefits of internationalization of higher education can be analyzed at four levels: student, institution, domestic, and global. From the student level, the internationalization of education is effective in assisting students to enrich their knowledge, enhance students' language competences, and lift students' international competitiveness. At the institution level, educational institutions are able to heighten their reputation, build multicultural campuses, and generate revenues from tuition and subsidies. Furthermore, the internationalization of education may also allow nations to create cultural diplomacy, consolidate national identity, and generate revenues from educational exports. Finally, in terms of global benefits, the internationalization of education is crucial in sustaining international knowledge exchange, nurturing respect for cultural diversity, and building a sense of global citizenship.

In Taiwan, the White Paper of International Education for Primary and Secondary Schools established a variety of implementation objectives that can be classified into four dimensions. The dimension of national identity comprises the objectives of appraising the culture of the home country, understanding the international status of the home country, and cultivating patriotism. The dimension of international literacy comprises the objectives of recognizing different cultures, enhancing intercultural communication skills, and knowing international and global issues. The dimension of global competition/cooperation comprises the objectives of strengthening English skills, nurturing keen observation in intercultural comparisons, and enriching international cooperation experiences. Finally, the dimension of global responsibility comprises the objectives of respecting and comprehending different cultures, concerning international affairs, and building concepts of global responsibility.

Although Taiwan's government identified the major objectives of fostering international education, they are of different importance to each school facing its specific environmental context. Therefore, this research sought to examine the relative importance of each objective of international education to schools with different backgrounds in Taiwan. 


\subsection{International Academic Exchange Programs}

International academic exchange is one of the most popular forms in international education. In Taiwan, the White Paper of International Education for Elementary and Secondary Schools identified the major implementation approaches for carrying out international academic exchanges, which include study abroad, educational travels, international service volunteers, internet international communication, and establishment of international sister (affiliated) schools, and participation in international competitions. Each implementation approach has its own strengths and weaknesses in accomplishing the goals of international education, and different implementation approaches might be adequate for some schools but not for others. Therefore, rather than adopting all of the implementation approaches, schools have to select those implementation approaches that are best in line with their environmental context.

A variety of overseas learning options are popular in Taiwan. Bamber (2014) conducted research on Chinese students studying in other countries and argued that overseas study experiences are beneficial to students because they not only learn the latest knowledge and experiences at overseas schools, but will also earn a better salary after graduation. Meanwhile, higher tuition and living costs are the major obstacles deterring students from studying abroad.

Grothus (2003) concluded that international academic cooperation among institutions is beneficial to both institutions and participating students and faculty. The exchange approaches often encourage intercultural dialog and understanding, thereby enriching participants' experiences of dealing with problems caused by cultural differences. Recently, Welling et al. (2017) also asserted the gigantic benefit of international academic exchange programs, arguing that global academic exchanges often create mutual significant benefits for participants from both sides. However, Sato and Hodge (2015) concluded that, although most research results suggest that international academic exchange programs are beneficial, students might feel like unwelcomed foreigners in their major courses and benefit less if the program is not well designed.

Tepper (2016) argued that international volunteer services can help students improve their abilities in dealing with people from different cultural backgrounds, enhancing their frustration-tolerance abilities, and learning how to use their limited resources efficiently. Moreover, Foster, Yao, Buchanan-Butterfield, and Powell-Brown (2013) further stressed that the mobility of students across national borders provides mutual benefits. Students studying abroad may benefit from learning the latest knowledge and experiences of other countries while students in the host countries are also gaining invaluable opportunities to acquire cultural understandings and enhance their language capabilities without necessarily traveling abroad.

Thanks to technological advancements, a new approach to school exchange and cooperative programs has emerged through the internet. Hsin, Wang, and Huang (2014) conducted a case study on internet language exchange programs; they argued that the recent acceleration of internet development has further alleviated the obstacles of cooperation between institutions in different countries. Their research results indicated that internet academic exchange programs successfully enhanced the Chinese language ability of high school students in the United States while simultaneously helping teachers from China and Taiwan hone their skills in teaching Chinese and promoting Chinese language to the global society.

Building on the strengths and weaknesses of the international exchange programs, we are interested in figuring out what international exchange programs can best accomplish the international education goals set by the Taiwan government. The research design will be discussed in the following section on methodology.

\section{Methodology}

Analytic hierarchy process (AHP) was adopted in this research as the major method for calculating the relative importance of each of the international academic exchange objectives. AHP is a popular method in multi-criteria decision-making analyses. This approach separates a big problem into smaller problems; researchers then solve the smaller problems one by one to get a better chance to tackle the big problem more thoroughly in the end. The most noticeable function of AHP is calculating the relative weights of decision standards and selecting a policy option from a number of competing alternatives (Ho, Lin, and Yang, 2015). As this research is aimed at evaluating the relative importance of each of the international academic exchange objectives, we assumed that AHP would be the best method for accomplishing our research objectives.

The most critical process of conducting an AHP research is to develop a hierarchical structure, where factors in the same layer belong or bare answers to the upper layers while serving as the dominating factors in the lower layers (Wu et al., 2016). The AHP structure not only allows researchers to gain a better understanding of the whole problem sets, but it also contributes to cutting down the number of questions included on questionnaires, 
thereby easing the burden for research participants (Wu et al., 2016).

Thus, an AHP structure was developed for this research. The first level was the main purpose: accomplishing the official goals of international education at primary and secondary schools as announced in Taiwan's white paper published in 2011. Four dimensions of international exchange objectives were then assigned to the second level: national identity, international literacy, global competition/cooperation, and global responsibility. Each dimension was composed of three objectives, as shown in Figure 1. Based on this hierarchy structure, a self-developed AHP questionnaire was administered to school principals in Taiwan.

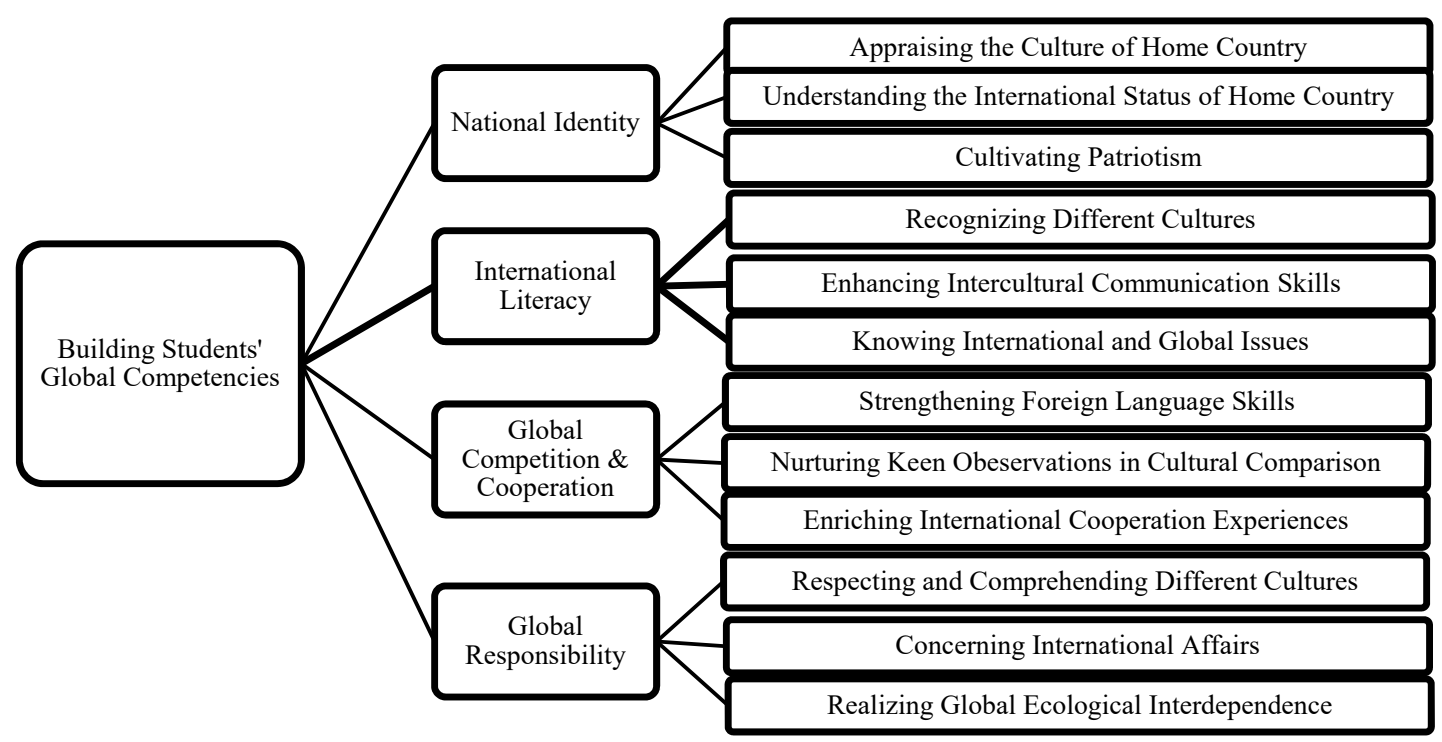

Figure 1. AHP structure

School principals play the most important role in implementing international exchange programs in Taiwan. They are responsible for receiving and understanding the government's international academic exchange policies, developing school operational plans to carry out the government's policies, persuading school members to participate in the programs, and assisting school members to successfully accomplish the goals. Therefore, we determined that school principals should be the target group for this research. The questionnaire for this research was delivered to 20 school principals who had at least 2 years of experiences in implementing international exchange programs in Taiwan. Of these participants, $75 \%$ were male and only $25 \%$ were female; $70 \%$ of the participants were from schools located in rural areas while 30\% were from schools located in cities.

\section{Research Results}

We first compared the relative importance of the four dimensions. The research results indicated that the importance of the four dimensions was very similar. Global competition/cooperation was perceived by principals as being slightly more important than other dimensions, followed by international competence, global responsibility, and national identity. A possible reason for this result may be explained by the general belief that the internationalization of education is promoted by the government to nurture a high quality workforce with international knowledge and skills to survive the highly globalized market competitions. Therefore, principals perceived global competition/cooperation as the most important dimension for international education in Taiwan.

Table 1. Weight of the Four Dimensions Perceived by All Participants

\begin{tabular}{lll}
\hline Dimension & Weight & Ranking \\
\hline Global responsibility & 0.25 & 3 \\
Global competition \& cooperation & 0.29 & 1 \\
International competence & 0.26 & 2 \\
National identity & 0.20 & 4 \\
\hline
\end{tabular}


We then compared the relative importance of the 12 objectives of international exchange. The research results indicated that realizing the interdependence of global ecology, building keen observations in cultural comparison, and knowing international and global issues were the three most important objectives perceived by school principals, followed by enriching international cooperation experiences. In contrast, cultivating patriotism and appraising the culture of the home country were considered to be the least important objectives.

Table 2. Weight of the Twelve Objectives Perceived by All Participants

\begin{tabular}{lll}
\hline Dimension & Objectives & Weight \\
\hline \multirow{3}{*}{ National identity } & Appraise the culture of home country & 0.06 \\
& Identify the international status of home country & 0.08 \\
& Cultivating patriotism & 0.05 \\
& Understanding other cultures & 0.08 \\
International competence & Learning intercultural communication & 0.08 \\
& Knowing critical international and global issues & 0.11 \\
Global competition \& cooperation & Strengthen foreign language skills & 0.07 \\
& Keen observation on cultural comparatives & 0.11 \\
Global responsibility & Enriching international cooperation experiences & 0.10 \\
& Respecting and comprehending different cultures & 0.07 \\
& Concerning international affairs & 0.07 \\
\hline
\end{tabular}

Then we compared the perceptions of male and female principals of the importance of international exchange objectives. The research results indicated that female and male principals had very different opinions. Male principals tended to stress identifying the international status of the home country, appraising the culture of the home country, and knowing international and global issues whereas female principals tended to put significantly more importance on learning intercultural communication skills.

Table 3. Weight of the Twelve Objectives Perceived by Male and Female Participants

\begin{tabular}{|c|c|c|c|c|}
\hline & & & Male & Female \\
\hline \multirow{2}{*}{\multicolumn{2}{|c|}{ Dimension }} & Objectives & Weight & Weight \\
\hline & & Appraise the culture of home country & 0.07 & 0.04 \\
\hline \multirow{3}{*}{\multicolumn{2}{|c|}{ National identity }} & Identify the international status of home country & 0.10 & 0.05 \\
\hline & & Cultivating patriotism & 0.06 & 0.04 \\
\hline & & Understanding different cultures & 0.08 & 0.05 \\
\hline \multirow[t]{3}{*}{ International competence } & & Learning intercultural communication & 0.04 & 0.20 \\
\hline & & Knowing international and global issues & 0.11 & 0.08 \\
\hline & & Strengthening foreign language skills & 0.09 & 0.06 \\
\hline \multirow{3}{*}{$\begin{array}{l}\text { Global } \\
\text { cooperation }\end{array}$} & $\&$ & Building keen observations in cultural comparisons & 0.12 & 0.10 \\
\hline & & Enriching international cooperation experiences & 0.09 & 0.12 \\
\hline & & Respecting and comprehending different cultures & 0.08 & 0.06 \\
\hline \multirow[t]{2}{*}{ Global responsibility } & & Concerning international affairs & 0.06 & 0.08 \\
\hline & & Realizing the interdependence of global ecology & 0.11 & 0.11 \\
\hline
\end{tabular}

We also compared the differences between elementary and junior high school principals. The research results indicated that principals from the two research levels revealed very similar perceptions of the four dimensions. Elementary school principals stressed international competences slightly more than their junior high school counterparts whereas junior high school principals emphasized national identity somewhat more than elementary school principals. 
Table 4. Weight of the four goals Perceived by Primary and Junior High School Participants

\begin{tabular}{lllcc}
\hline & $\begin{array}{l}\text { Primary } \\
\text { school }\end{array}$ & & \multicolumn{2}{c}{ Junior high school } \\
Dimension & Weight & Ranking & Weight & Ranking \\
\hline National identity & 0.18 & 4 & 0.21 & 4 \\
International competence & 0.33 & 1 & 0.27 & 2 \\
Global competition/ cooperation & 0.27 & 2 & 0.28 & 1 \\
Global responsibility & 0.23 & 3 & 0.23 & 3 \\
\hline
\end{tabular}

We then compared the differences between elementary and junior high school principals on their perceptions toward the importance of international exchange objectives. The results indicated that primary school principals tended to stress understanding different cultures, learning intercultural communication, and knowing international and global issues somewhat more. In contrast, junior high school principals had more to say about appraising the culture of the home country, identifying the international status of the home country, and cultivating patriotism. In general, the differences in opinion between elementary and junior high school principals toward the objectives of international academic exchange were very small.

Table 5. Weight of the Twelve Objectives Perceived by Primary and Junior High School Participants

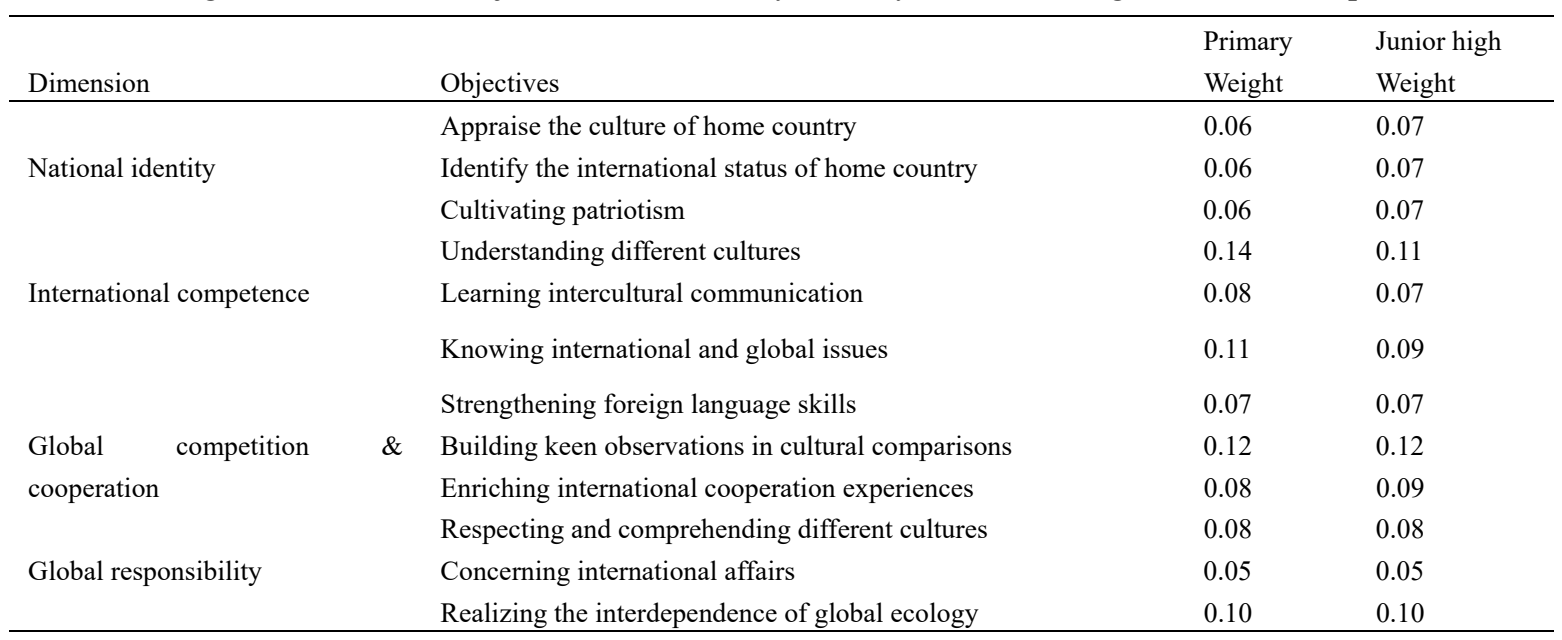

We were also interested in identifying any differences between principals of schools in rural areas versus cities. The research results indicated that principals in rural area tended to emphasize global responsibility and international competences whereas principals in cities put more importance on global competition/cooperation and national identity.

Table 6. Weight of the four goals Perceived by City and Rural Participants

\begin{tabular}{lllcl}
\hline & City & & \multicolumn{2}{c}{ Rural } \\
Dimension & Weight & Ranking & Weight & Ranking \\
\hline National identity & 0.30 & 2 & 0.16 & 4 \\
International competence & 0.21 & 3 & 0.28 & 2 \\
Global competition/cooperation & 0.31 & 1 & 0.27 & 3 \\
Global responsibility & 0.18 & 4 & 0.29 & 1 \\
\hline
\end{tabular}

We also compared the differences between principals from different areas in terms of the objectives of international academic exchange. The results indicated that principals from schools located in rural areas more heavily stressed realizing the interdependence of global relations, enriching international cooperation, concerning international affairs, and knowing international and global issues. In contrast, principals from schools located in cities tended to focus on strengthening competence in cultural communication, strengthening foreign language skills, understanding different cultures, cultivating patriotism, identifying the international status of the home country, and appraising the culture of the home country. 
Table 7. Weight of the Twelve Objectives Perceived by City and Rural Participants

\begin{tabular}{|c|c|c|c|c|}
\hline Dimension & & Objectives & $\begin{array}{l}\text { City } \\
\text { Weïght }\end{array}$ & $\begin{array}{l}\text { Rural } \\
\text { Weight }\end{array}$ \\
\hline \multirow{3}{*}{ National identity } & & Appraise the culture of home country & 0.05 & 0.07 \\
\hline & & Identify the international status of home country & 0.13 & 0.06 \\
\hline & & Cultivating patriotism & 0.11 & 0.04 \\
\hline \multirow{3}{*}{ International competence } & & Understanding different cultures & 0.10 & 0.06 \\
\hline & & Learning intercultural communication & 0.06 & 0.08 \\
\hline & & Knowing international and global issues & 0.05 & 0.14 \\
\hline \multirow{3}{*}{$\begin{array}{l}\text { Global } \\
\text { cooperation }\end{array}$} & & Strengthening foreign language skills & 0.11 & 0.06 \\
\hline & $\&$ & Building keen observations in cultural comparisons & 0.13 & 0.09 \\
\hline & & Enriching international cooperation experiences & 0.07 & 0.11 \\
\hline \multirow{3}{*}{ Global responsibility } & & Respecting and comprehending different cultures & 0.08 & 0.07 \\
\hline & & Concerning international affairs & 0.04 & 0.09 \\
\hline & & Realizing the interdependence of global ecology & 0.07 & 0.13 \\
\hline
\end{tabular}

Finally, we tried to determine what international academic exchange approaches might efficiently accomplish specific objectives of international academic exchange. The results (see Figure 2) indicated that partner schools are a good way to accomplish the objectives of cultural comparison and international cooperation; international volunteers are effective for achieving the objectives of multicultural understanding and respecting and appraising other cultures; internet communication is efficient in understanding international affairs; participating in international competitions is an efficient way for knowing the status of the home country; and conducting English villages is effective for enhancing English capacities.

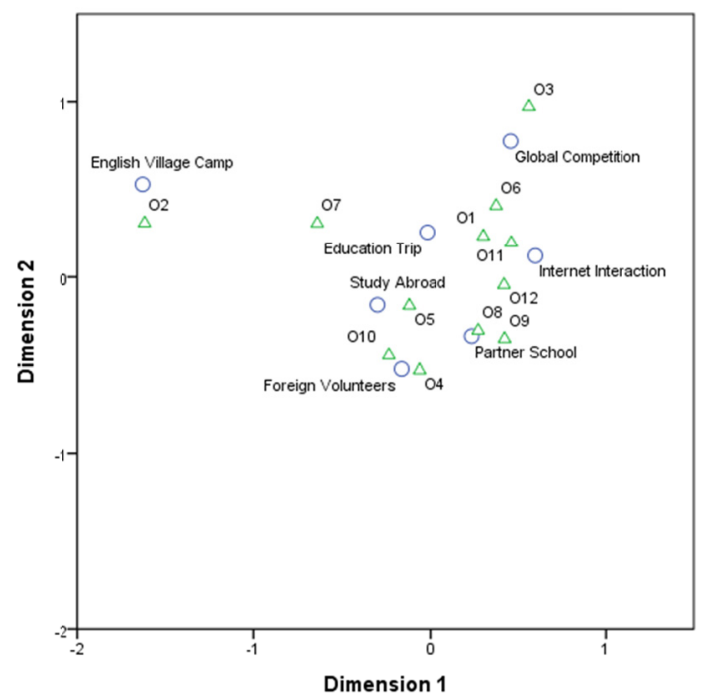

Figure 2. Correspondence Analysis of implementation approaches on International Exchange Objectives Note:

O1: Appraising the Culture of Home Country

O2: Understanding the International Status of Home Country

O3: Cultivating Patriotism

O4: Recognizing Different Cultures

O5: Enhancing Intercultural Communication Skills

O6: Knowing International and Global Issues

O7: Strengthening Foreign Language Skills

O8: Nurturing Keen Observations in Cultural Comparison 


\section{O9: Enriching International Cooperation Experiences}

O10: Respecting and Comprehending Different Cultures

\section{O11: Concerning Essential International Affairs}

O12: Realizing Global Ecological Interdependence

\section{Conclusion}

To survive and thrive in the current fiercely competitive globalized and knowledge-based economy environment, it is of utmost importance to identify the best option from a huge pool of alternatives. We expect that the research findings discussed herein will provide school principals with practical information for determining their best international exchange approaches.

In this research, we tried to identify the major objectives of fostering the international academic exchange programs at the elementary and junior high school levels in Taiwan. We also sought to determine which international exchange approach was more effective in carrying out the aforementioned objectives. As principals play a key role in carrying out the international academic exchange programs, they were targeted as the major participants in this research.

The research results showed that principals stress mostly on the objectives of realizing the interdependence of global ecology, building keen observations in cultural comparison, and knowing international and global issues, while put less importance on the objectives of cultivating patriotism and appraising the culture of the home country. One possible reason for these research results is the widespread belief that understanding and recognizing the competitive environment is the first step in surviving the global competition; therefore, the highest scores were given to objectives related to understanding the global environment. We would thus highly suggest that schools in Taiwan strengthen students' capabilities in distinguishing between true and false international information, develop an adequate curriculum to enhance students' observations, and seek extra funds to ensure that students are having good firsthand experiences in international communications and cooperation.

The research results also indicated that different international exchange approaches may contribute to certain objectives more efficiently than to others; therefore, it is important for principals to select the right international exchange approaches to fit their unique environmental and educational focus.

Finally, from the t-test results indicated that male principals tend to stress identifying the international status of the home country, and appraising the culture of the home country, while female principals emphasize the objective of learning intercultural communications. A possible reason for this difference is that almost all male principals enlisted in the military for at least two years, where they learned that obeying the demands of the country is crucial; therefore, they tended to give higher scores to objectives related to the recognition of their home country. Meanwhile, many psychological theories have stressed that females tend to use more communicational methods to solve problems than males; as a result, female principals in this research gave significantly higher scores than their male counterparts in appreciating intercultural communications. It is important to stress that although we provided possible explanations for the results concerning differences between male and female principals, the explanations were not proved by any empirical research, and therefore, they could only be treated as speculations or hypothesis that should be examined in the future. We would therefore strongly suggest that an in-depth qualitative research be conducted in the future to examine the accuracy of those explanations.

\section{References}

Bamber, M. (2014). What motivates Chinese women to study in the UK and how do they perceive their experience. Higher Education, 68(1), 47-68. https://doi.org/10.1007/s10734-013-9679-8

Beerkens, E. (2008). University policies for the knowledge society: Global standardization, local reinvention. Perspectives on Global Development and Technology, 7(1), 15-36. https://doi.org/10.1163/156914907X253242

Childress, L. K. (2009). Planning for internationalization by investing in faculty. Journal of International and Global Studies, 1(1), 30-49.

Foster, K. K., Yao, Y., Buchanan-Butterfield, D. L., \& Powell-Brown, A. (2013). Spreading our wings: International education as journeys of enriched learning. Multicultural Perspectives, 15(3), 168-173. https://doi.org/10.1080/15210960.2013.809308 
Gao, Y. (2015). Constructing internationalization in flagship universities from the policy-maker's perspective. Higher Education, 70, 359-373. https://doi.org/10.1007/s10734-014-9834-x

Grothus, U. (2003). The contribution of international academic co-operation and exchange to the development and advancement of society. Higher Education in Europe, 28(1), 109-111. https://doi.org/10.5539/ies.v8n3p55

Ho, H., Lin, M., \& Yang, C. (2015). Goals, strategies, and achievements in the internationalization of higher education in Japan and Taiwan. International Education Studies, 8(3), 55-65. https://doi.org/10.5539/ies.v8n3p55

Hsin, S., Wang, C., \& Huang, Y. (2014). An international cooperative model of online Chinese courses. Journal of Humanities and Arts Computing: A Journal of Digital Humanities, 8, 95-106. https://doi.org/10.3366/ijhac.2014.0101

Minchul, S., Jeonghoon, M., Kyungsik, L., \& Cheol, L. (2017). on the interval selection and interpretation of the probabilistic AHP for uncertain decision making. International Journal of Industrial Engineering, 24(1), $32-43$.

Pandit, K. (2009). Leading internationalization. Annals of the Association of American Geographers, 99(4), 645-656. https://doi.org/10.1080/00045600903120552

Sato, T., \& Hodge, S. R. (2015). Academic and social experiences of exchange students from Japan attending an American university. College Student Journal, 49(1), 78-92.

Seeber, M., Cattaneo, M., Huisman, J., \& Paleari, S. (2016). Why do higher education institutions internationalize? An investigation of the multilevel determinants of internationalization rationales. Higher Education, 72, 685-702. https://doi.org/10.1007/s10734-015-9971-x

Tepper, D. (2016). Making the most of international volunteer and learning opportunities. PT in Motion, 8(10), 16-23.

Welling, D., Villavicencio, L., Wherry, D., Jindal, R. M., Elster, E. A., \& Rich, N. M. (2017). Medical students and international exchanges: An underappreciated aspect of global surgery. Military Medicine, 182(5), 1566-1567. https://doi.org/10.7205/MILMED-D-17-00037

Wu, X., Li, R., Cao, Y., Ni, Y., Xu, X., \& Qian, X. (2016). The value network optimization research based on analytic hierarchy process method and the dynamic programing of cloud manufacturing. International $\begin{array}{llll}\text { Journal of Advanced Manufacturing Technology, } & \text { 84(1-4), 425-433. }\end{array}$ https://doi.org/10.1007/s00170-015-8198-4

Youssef, L. (2014). Globalization and higher education: From within-border to cross-border. Open Learning, 29(2), 100-115. https://doi.org/10.1080/02680513.2014.932686

\section{Copyrights}

Copyright for this article is retained by the author(s), with first publication rights granted to the journal.

This is an open-access article distributed under the terms and conditions of the Creative Commons Attribution license (http://creativecommons.org/licenses/by/4.0/). 